\title{
Comparison of Two Methods of Chlorhexidine Application of Shear Bond Strength Degradation between Composite Resin and Dentin
}

\author{
Endang Suprastiwi ${ }^{1}$, Itja Risanti², Nila Kesuma Djauharie ${ }^{1}$ \\ ${ }^{1}$ Department Conservative Dentistry, Faculty of Dentistry, Universitas Indonesia, Depok, Indonesia \\ ${ }^{2}$ Department Dentistry, Fatmawati Hospital, Jakarta, Indonesia \\ Email: esuprastiwi@yahoo.co.id
}

Received 29 June 2015; accepted 7 August 2015; published 10 August 2015

Copyright (C) 2015 by authors and Scientific Research Publishing Inc.

This work is licensed under the Creative Commons Attribution International License (CC BY). http://creativecommons.org/licenses/by/4.0/

\begin{abstract}
Background: Chlorhexidine could have effect on shear bond strength of composite resin-dentin. Objective: The purpose of this study is to compare two methods of chlorhexidine application of shear bond strength degradation between composite resin and dentin. Methods: Thirty samples of dentin were taken from the crown of premolars and then divided into three groups $(n=10)$. Group 1 were applied bonding without chlorhexidine, group 2 were applied with liquid chlorhexidine and followed by bonding, group 3 were applied bonding which contains chlorhexidine. Each group was divided into two sub-groups $(n=5)$ : the group with and without $10 \% \mathrm{NaOCl}$ immersion for one hour. Then, 4 samples in each sub-group were used to measure shear bond strength using Universal Testing Machine, and 1 sample was examined with Scanning Electron Microscope (SEM). Data were analyzed using SPSS 17 by Mann-Whitney and Kruskal Wallis test. Results: The highest mean shear bond strength without $10 \% \mathrm{NaOCl}$ immersion was in group 1 , while the highest mean with $10 \% \mathrm{NaOCl}$ immersion was in group 3. Significant differences occurred between the groups 1 and 2, groups 2 and 3. Conclusion: Method of using bonding contains chlorhexidine can increase and inhibit degradation shear bond strength between composite resin and dentin.
\end{abstract}

\section{Keywords}

Chlorhexidine, Composite Resin, Dentin, Shear Bond Strength 


\section{Introduction}

Failure of composite resin restorations occurs within times. This is due to the bonding of composite resin dental tissue degradation due to mechanical forces and chemical occurring in the oral cavity [1] [2]. Composite resindentin bonds have characteristics which related with water content and collagen of dentin [3]. In vitro and in vivo studies showed that the adhesive bond failure allows the penetration of enzymes, mouth cavity fluid, and bacteria into the gap formed between the teeth and composite resin restorations [4] [5].

Degradation of composite resin-dentin bonds may occur due to moisture absorption, hydrolysis of methacrylate resin, as well as the activation of dentin endogenous enzyme [1] [5] [6]. Matrix metalloproteinase (MMP) is an endoproteinase group found in human dentin which are MMP-2, MMP-8 and MMP-9, that of enzyme activities directly to the extracellular matrix components causing biodegradation of dentin [5]-[8]. This enzyme has the effect of destroying collagen and extracellular matrix. A number of studies suggested that dormant enzymes can be found in dentin and activated by the acidity of the etching on the total-etch adhesive systems [5] [6] [9]. Once activated, this enzyme would destroy the collagen fibrils that are not infiltrated by resin under the hybrid layer. It broke covalent bonds and slowly eroded the collagen fibers [2] [5] [6] [9] [10].

Chlorhexidine is a disinfectant that can bind to the bacterial cell membrane which causes bacterial cell death. Chlorhexidine as a broad-spectrum MMP inhibitor, Hebling et al. (2005) stated that the application of chlorhexidine after etching will have a hybrid layer with better collagen integrity after six months period [11]. De Munck et al. (2009) stated that chlorhexidine was effective as an MMP inhibitor on total-etch adhesive, but did not show significant result on self-etch adhesive. That study also noted that chlorhexidine could inhibit the infiltration of resin into the hybrid layer [12]. The addition of chlorhexidine into the bonding could enhance the long-term strength [13]-[15]. Rahmayanti study in 2011 compared the effects of chlorhexidine and glutaraldehyde on shear bond strength of composite resin-dentin by the method of storage on artificial saliva for 1 and 30 days. The results showed that the application of $2 \%$ chlorhexidinegluconate and $5 \%$ glutaraldehyde could increase the strength of composite resin-dentin, with chlorhexidine had greater value than glutaraldehyde [16]. Chlorhexidine in the market exists in a variety of dosage forms which are $2 \%$ chlorhexidinegluconate liquid used in addition to the composite resin bonding application, and the other one is chlorhexidine-contained bonding. Chlorhexidine liquid applied after etching the dentin on total-etch adhesives or before primer application on self-etch adhesives.

This study is to compare two methods of chlorhexidine application of shear bond strenght degradation between composite resin and dentin.

\section{Materials and Methods}

Dentin samples were taken from human premolar teeth which were extractedless than one month before study conducted, then immersed in $0.9 \% \mathrm{NaCl}$ solution (saline). Sample inclusion using upper or lower premolar which indicate to extracted for orthodontic reason. Buccal parts of teeth were removed and flattened with a carborundum disc low speed under the water flow. Then the roots of teeth disposed with the same type of bur. Tooth crown without root were dried, formed to be slab and planted in self-cured acrylic resin pipe with diameter of $1 \mathrm{~cm}$ and height of $2 \mathrm{~cm}$. Dentin surface covered up with sticky paper to prevent acrylic resin entrance to the surface of the sample. After that, dentin surface were exposed using sandpaper No. 500 rotated by Labofor III machine under running water, which has been shown to have the same roughness with carborundum bur disc.

The numbers of samples in accordance with the Federer formula were 30 samples :

$$
\begin{aligned}
(t-1)(r-1) & \geq 15 \rightarrow(3-1)(10-1) \rightarrow 18 \geq 15 \\
t & =\sum \text { experiment group } \\
r & =\sum \text { sample of each group }
\end{aligned}
$$

The entire surface of the samples were etched with 37\% phosphoric acid (Ultra-etch, Ultradent Product Inc. USA) for 20 seconds, rinsed with water for 5 seconds and dried with light air spray. Then samples were divided into three groupsrandomly, each of them were 10 sampels. Group 1, applied bonding without chlorhexidine (PQ1, Ultradent Product Inc. USA) and then continued application of composite resin (Amelogen Plus, Ultradent Product Inc. USA). Group 2, applied 2\% chlorhexidine liquid (Consepsis, Ultradent Product Inc. USA), dried, applied bonding (PQ1, Ultradent Product Inc. USA) and then applied composite resin (Amelogen 
Plus, Ultradent Product Inc. USA). Group 3, applied 0.2\% chlorhexidine-contained bonding (Peak Universal Bond, Ultradent Product Inc. USA) continued application of composite resin (Amelogen Plus, Ultradent Product Inc. USA). The entire samples were immersed in artificial saliva and kept in an incubator for 24 hours at $37^{\circ} \mathrm{C}$. Groups were divided into two subgroups, each of them were 5 samples. In each subgroup, 4 samples tested their shear bond strengths and 1 sample was examined by SEM.

\section{Statistical Analysis}

Analyzed by using SPSS 17, mean and standard deviation were estimated for each group. Normality of the data was tested in each group by using Saphiro-Wilk test. The data has a normal distribution and is not homogeneous then performed Kruskal-Wallis followed by Mann-Whitney test. Statistical significance was defined as $P<0.05$.

\section{Results}

The effects of the various methodon the shear bond strength of composite resin-dentin are shown in the Table 1.The maximum shear bond strength of Group without 10\% NaOCl immersion in Group1 (7.35 \pm 3.61), followed by Group $3(5.34 \pm 2.32)$ and Group $2(1.75 \pm 0.44 .33)$. On the Group with $10 \% \mathrm{NaOCl}$ immersion the maximum shear bond strenght in Group 3 (7.35 \pm 2.70), followed Group 1 (4.07 \pm 1.76$)$ and Group 2 (1.35 \pm 049). The mean of shear bond strength in group 1 and group 2 after $10 \% \mathrm{NaOCl}$ immersion were decreased, while in group 3 were increased. Standar deviation of shear bond strength in this study was calculated as a measure of values spread per group. The biggest distribution of group value was in Sub-group 1 (without 10\% $\mathrm{NaOCl}$ immersion), while the smallest distribution of group value was in Sub-group 2 (without $10 \% \mathrm{NaOCl}$ immersion). Significant differences on between group 1 to group $2(p=0.021)$, group 2 to group $3(p=0.021)$, both on the non-immersed and $10 \% \mathrm{NaOCl}$ immersed group ( $\mathrm{p}=0.021)$.

The SEM analysis result on Figure 1 On the Group 2 showed thin hybrid layer before and after $10 \% \mathrm{NaOCl}$ immersion. On Group 1 and Group 3 showed thick hybrid layer, while hybrid layer in Group 3 after 10\% NaOCl immersion to increase.

\section{Discussion}

This study comparative and analyzed the effect of two methods of chlorhexidine application on the composite resin-dentin bond strength degradation. Degradation of bond strength between the restoration and tooth tissue happened due to continuous use over a long period. It could occur because of various physiological irritants, mechanical, chemical and intrinsic factor from the teeth itself. Dentin are the part of dental hard tissues, composed of $70 \%$ inorganic material in the form of hydroxyapatite crystals, $15 \%-20 \%$ organic material in the form of collagen, $1 \%$ - $2 \%$ non-collagen and $10 \%-12 \%$ water [17] [18]. Composite resin is a dental restorative material which is bonded to dentin by composite resin monomer infiltration into the demineralized dentin. This bond is very critical because it were affected by high water content and organic matter [18]. MMP enzymes in dentin are a kind of endoproteinase enzyme that have a role to degradation of extracellular matrix components of dentin and also affects the bond between resin composite to dentin [5] [6] [9]. Chlorhexidin (CHX) 2\% is a well-known cavity disinfectant before restoration applied which since 1999 Gendron et al. introduced it as a broad spectrum MMP inhibitor. It is also stated by Singla (2011) that CHX may cause calcium retention in the hybrid layer so that the dentine underneath becomes more resistant to acid [19]. To optimize the function of CHX as an MMP inhibitor, Botelho (2005) recommends to apply CHX after acid etching and before bonding application [20] whereas now available CHX-contained bonding. This study compared two different application methods i.e. liquid CHX which applied before bonding and CHX-contained bonding.

Measuring the bond strength between resin composite and dentin tissue could be tested by shear bond strength and/or tensile bond strength test. In the current study, shear bond strength were chosen because this method can describe a connective force between two different objects. SEM analysis was used to see microscopic picture of the relationship between composite resin and dentin.

Depicting oral cavity condition in a long period of time, there are several methods to choose, this study were used 10\% NaOCl immersion for one hour. Based on Yamauti (2003) research, $10 \% \mathrm{NaOCl}$ could made nonspecific deproteinized and also dissolve dentin organic matrix mainly protein collagen fibrils to accelerate bonds degradation in resembling mouth conditions over 4 years period [21]. 
Table 1. Comparison of mean values among different method groups.

\begin{tabular}{cccc}
\hline Treatment & Group & Mean \pm S.D & Significant Group \\
\hline & 1 & $7.35 \pm 3.61$ & 1 vs 2 \\
Without 10\% NaOCl Immersion & 2 & $1.75 \pm 0.44$ & 2 vs 3 \\
& 3 & $5.34 \pm 2.32$ & 1 vs 2 \\
With 10\% NaOCl Immersion & 1 & $4.07 \pm 1.76$ & 2 vs 3 \\
\hline
\end{tabular}

Without $10 \% \mathrm{NaOCl}$ immersion
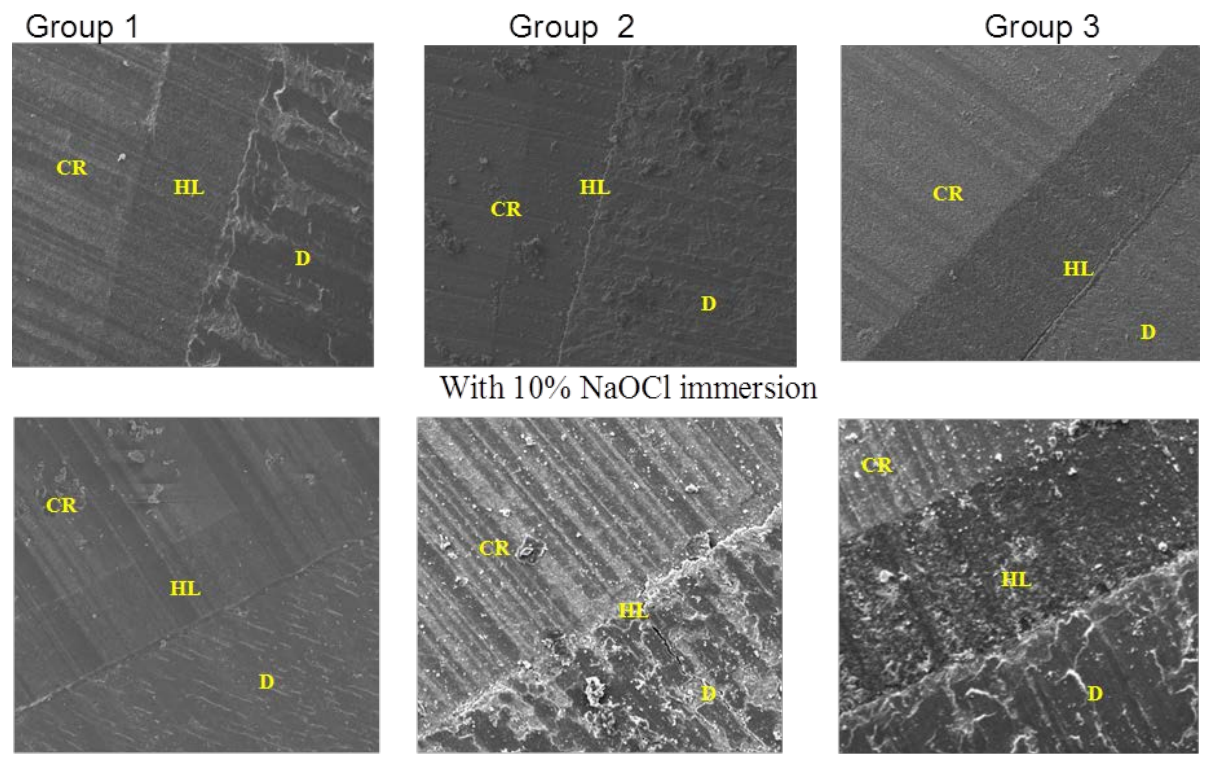

$\mathrm{CR}=$ composite resin, $\mathrm{HL}=$ hybridlayer, $\mathrm{D}=$ dentin.

Figure 1. SEM analysis of sub-group.

In Table 1, it can be seen that there was a decrease in shear bond strength of Group 1 (bonding) after 10\% $\mathrm{NaOCl}$ immersion from 7.35 to $4.07 \mathrm{MPa}$, whereas increase in Group 3 (CHX-contained bonding) after $10 \%$ $\mathrm{NaOCl}$ immersion from 5.34 to $7.23 \mathrm{MPa}$. It means that the content of $\mathrm{CHX}$ in the bonding could inhibited degradation and increases the bond strength of composite resin and dentin tissue. This result is consistent with Carrilho (2007) who stated that the bond strength between composite resin-dentin then applied with CHX for 60 seconds, after 14 months proved to have bond strength and morphological structure similar to specimens stored for 24 hours [8]. Different to other groups, in Group 2 (CHX liquid and bonding) the bond strength after 10\% $\mathrm{NaOCl}$ immersion was decreased from 1.75 to $1.35 \mathrm{MPa}$ with value smaller than Group 1 and 3 . It might be due to liquid form of CHX which made application more difficult to be controlled. This condition can be seen in the SEM picture, Group 2 did not seem to have (or maybe too thin) the hybrid layer.

To compared between each group were before and after immersion of $10 \% \mathrm{NaOCl}$ it looks like there were no significant differences. Meanwhile, when three groups were compared, there are significant differences between Group 1 and 2; Group 2 and 3 (with and without 10\% $\mathrm{NaOCl}$ immersion). These results were confirmed in Figure 1, Group 1 and 3 have thick hybrid layer between the resin composite and dentin, while Group 2 had almost none/thin hybrid layer. Carrilho et al. stated that the application of CHX failed to strengthen bond between composite resin-dentin because of hydrolytic degradation of the polymer resin composite, not the collagen fibers. If there were no CHX application, the bond failures happened mostly because of hydrolysis of collagen fibers [9].

Results of this study contrasted with Sabatini (2012) statement, that the CHX, both in 2\% CHX liquid or $0.2 \%$ CHX-contained bonding, showed no significant difference in the shear bond strength when compared with the 
control group without CHX after a period of 24 hours. The difference was due to different aging acceleration methods, Sabatini analyzed after 24 hours immersion in saline, whereas in this study used $10 \% \mathrm{NaOCl}$ immersion [13].

\section{Conclusion}

Chlorhexidine can increase shear bond strength between composite resin and dentin, also inhibit degradation of bond strength itself. Method of using bonding contains chlorhexidine which can increase shear bond strength resin composite-dentin.

\section{References}

[1] Mai, S., Gu, L.S. and Ling, J.Q. (2009) Current Methods for Preventing Degradation of Resin-Dentin Bonds. Hong Kong Dental Journal, 6, 83-92.

[2] Pashley, D.H., Tay, F.R. and Imazato, S. (2011) How to Increase the Durability of Resin-Dentin Bonds. Compendium of Continuing Education in Dentistry, 32, 60-64.

http://www.dentalaegis.com/cced/2011/09/how-to-increase-the-durability-of-resin-dentin-bonds

[3] Patil, R. (2002) Esthetic Dentistry: An Artist’s Science. P R Publications, Mumbai, Vol. 7, 95-98.

[4] Kostoryz, E.L., Dharmala, K., Ye, Q., Wang, Y., Huber, J., Park, J.G., Snider, G., Katz, J.L. and Spencer, P. (2009) Enzymatic Biodegradation of HEMA/BisGMA Adhesive Formulated with Different Water Content. Journal of Biomedical Materials Research Part B: Applied Biomaterials, 88B, 394-401. http://dx.doi.org/10.1002/jbm.b.31095

[5] Dundar, M., Ozcan, M., Cornlekoglu, M.E. and Sen, B.H. (2011) Nanoleakage Inhibition within Hybrid Layer Using New Protective Chemicals and Their Effect on Adhesion. Journal of Dental Research, 90, 93-98. http://dx.doi.org/10.1177/0022034510382547

[6] Helvey, G.A. (2012) Degradation of Dentin Bond Strengths-The Science Behind Restorative Long-term Success and Bonding Agents. Inside Dental Technology, 3. http://www.dentalaegis.com/idt/2012/01/degradation-of-dentin-bond-strengths.

[7] Borges, F., De Melo, M., et al. (2012) Antimicrobial Effect of ChlorhexidineDigluconate in Dentin: In Vitro and In Situ Study. Journal of Conservative Dentistry, 15, 22-25. http://dx.doi.org/10.4103/0972-0707.92601

[8] Carrilho, M.R., Geraldeli, S., Tay, F.R., De Goes, M.F., Carvalho, R.M., et al. (2007) In Vivo Preservation of the Hybrid Layer by Chlorhexidine. Journal of Dental Research, 86, 529-533. http://dx.doi.org/10.1177/154405910708600608

[9] Carrilho, M.R., Carvalho, R.M., De Goes, M.F., Hipolito, V., Geraldeli, S., Tay, F.R., Pashley, D.H. and Tjaderjane, L. (2007) Chlorhexidine Preserves Dentin Bond in Vitro. Journal of Dental Research, 86, 90-94. http://dx.doi.org/10.1177/154405910708600115

[10] Zou, Y., Jessop, J.L.P. and Armstrong, S.R. (2010) In-Vitro Enzymatic Biodegradation of Adhesive Resin in the Hybrid Layer. Journal of Biomedical Materials Research Part A, 94, 187-192. http://dx.doi.org/10.1002/jbm.a.32689

[11] Hebling, J., Pashley, D.H., Tjaderhane, L. and Tay, F.R. (2005) Chlorhexidine Arrests Subclinical Degradation of Dentin Hybrid Layers in Vivo. Journal of Dental Research, 84, 741-745. http://dx.doi.org/10.1177/154405910508400811

[12] De Munck, J., Van Landuyt, K., Peumans, M., Poitevin, A. and Lambrechts, P. (2005) A Critical Review of the Durability of Adhesion to Tooth Tissue: Methods and Results. Journal of Dental Research, 84, 118-129. http://dx.doi.org/10.1177/154405910508400204

[13] Sabatini, C. (2012) Effect of Chlorhexidine-Containing Adhesives on Early Dentin Shear Bond Strength. http://iadr.confex.com/iadr/2012tampa/webprogram/Paper157276.html

[14] Ultradent Products Inc. (2006) Consepsis \& Consepsis V: Chlorhexidine Antibacterial Solution. South Jordan.

[15] Ultradent Products Inc. (2011) Peak Universal Bond and Peak SE. South Jordan.

[16] Rahmayanti, A. (2008) Beberapa Cara dalam Menghambat Degradasi Ikatan Resin Dentin oleh Matriks Metalloproteinase. Departemen Konservasi Gigi FKGUI, Jakarta.

[17] Mount, G.J. (2005) Preservation and Restoration of Tooth Structure. 2nd Edition, Knowledge Books, Queensland, 200207.

[18] Tronstad, L. (2003) Clinical Endodontology: A Textbook. 2nd Edition, Thieme, Stuttgart, 1-5.

[19] Singla, M., Aggarwal, V. and Kumar, N. (2011) Effect of Chlorhexidine Cavity Disinfection on Microleakage in Cavities Restored with Composite Using a Self-Etching Single Bottle Adhesive. Journal of Conservative Dentistry, 14, 374-376. 
[20] Demarco, F.F., Turbino, M.L. and Matson, E. (1998) Tensile Bond Strength of Two Dentin Adhesive Systems. Brazilian Dental Journal, 9, 11-18.

[21] Yamauti, M., Hashimoto, M., Sano, H., Ohno, H., Carvalho, R.M. and Kaga, M. (2003) Degradation of Resin-Dentin Bonds Using NaOCl Storage. Dental Materials, 19, 399-405. 